\title{
Comparison of methods by micromycetes resistance to paint coatings and biocides
}

\author{
Tatiana Lisitskaia ${ }^{1, *}$ and Tatiana Velikova ${ }^{2}$ \\ ${ }^{1}$ Saint-Petersburg State Institute of Technology, Department Technology of Microbiological \\ Synthesis, 190013, St. Petersburg, Russia \\ ${ }^{2}$ The National Library of Russia, Federal Conservation Center for the Conservation of Library \\ Collections of the National Library of Russia, 18, Sadovaya street, 191069, St. Petersburg, Russia
}

\begin{abstract}
The study of fungal resistance of five paint coatings and three biocides by different methods was carried out using both individual cultures of micromycetes and their mixtures as test cultures. It is shown that the data obtained by different methods is almost identical, which makes it possible to use less labor-consuming and cheaper methods in establishing the fungal resistance of paint coatings and biocides.
\end{abstract}

\section{Introduction}

One of the significant problems is bio-damage by microscopic fungi of industrial and building materials, since this dramatically deteriorates their performance. The problem of contamination of residential, administrative and industrial premises with microscopic fungi is doubly harmful. Micromycetes are active biological destructors of both finishing and construction materials, and they are also human pathogens. Many micromycetes cause allergies, mycoses and mycotoxicoses, the likelihood of which increases significantly in an environment with a high content of these organisms. Microscopic fungi are capable of damaging most natural and synthetic materials used in industry and construction, causing biological damage [1-6]. Organic substances or paints and varnishes, which are applied to the outer layer of structures, also create favorable conditions for the development of mold fungi [2]. Micromycetes have both chemical and mechanical effects on building materials. Colonies of microscopic fungi mainly develop in microscopic cracks, in places with increased moisture content of concrete structures and brickworks [2]. Increased humidity causes wetting and softening of building materials, which is the main reason for the appearance of microscopic fungi and subsequent biological damage to finishing coatings and structures [5].

Molds occupy a dominant position among organisms that cause biological damage due to their morphological, physiological and genetic characteristics. In urban conditions, fungi occupy a special position among many microorganisms, both in terms of the number of species and the strength of their impact on the substrate on which they develop $[5,6]$. Micromycetes are able to use as a food source not only substances that are part of building and finishing materials, but also organic substances present in dust deposition on them.

* Corresponding author: lissitskayat@,rambler.ru 
In regulatory documents (Russian state standards) for the study of the resistance of materials to biological damage by fungi, it is necessary to use representatives of different genera of micromycetes, among which there are always species of the genera Aspergillus and Penicillium. Thus, the list of micromycetes used to study the fungal resistance of paint and varnish coatings includes two species of the genus Aspergillus and five species of the genus Penicillium: Aspergillus niger van Tieghem, A. terreus Thom, Alternaria alternata (Fr.) Keissler, Fusarium moniliforme Sheldon, Penicillium brevicompactum Dierckx, P. chrysogenum Thom, P. funiculosum Thom, P. ochro- chloron Biourge, P. martensii Biourge, Trichoderma viride Pers. ex Fr. For testing technical products, other than to optical parts, the following types of micromycetes are used: A. niger van Tieghem, A. terreus Thom, Aureobasidium pullulans (de Bary) Arnaud, Paecilomyces variotii Bainier, P. funiculosum Thom, P. ochro-chloron Biourge, Scopulariopsis brevicaulis Bainier, Trichoderma viride Pers. ex S. F.Gray. For testing optical parts use: A. penicilloides Speg, A. terreus Thom, Paecilomyces variotii Bainier, P. chrysogenum Thom, Scopulariopsis brevicaulis Bainier. For testing optical parts, use: A. penicilloides Speg, A.terreus Thom, Paecilomyces variotii Bainier, P. chrysogenum Thom, Scopulariopsis brevicaulis Bainier. A. penicilloides Speg, A. terreus Thom, Paecilomyces variotii Bainier, P. chrysogenum Thom, Scopulariopsis brevicaulis Bainier.

In addition to micromycetes specified in the standards for research on fungal resistance of materials and products, it should be taken into account that different regions have their own micromycete communities [7, 8]. So, according to the Research Institute of Medical Mycology in St. Petersburg and the Leningrad region, the main contaminants of residential premises are species of the genera Penicillium, Aspergillus, and Cladosporium [9]. The most common culturable airborne fungi, both indoors and outdoors and in all seasons and regions, were Cladosporium, Penicillium, and Aspergillus. Stachybotrys was identified in the indoorair in $6 \%$ of the buildings studied and in the outdoor air of $1 \%$ of the buildings studied [7]. In many homes, the levels of fungi were between 635 and $10,859 \mathrm{CFU} / \mathrm{m}^{3}$. The species of fungi identified were Penicillium, Aspergillus, Rhizopus, Mucor, Cladosporium, and Fusarium $[10,11]$.

The main methods for preventing bio-damage is coating materials with paints with biocidal properties or treating them with biocidal preparations, but the list of biocides that can be used for these purposes is small, since many biocides have toxic properties. Currently, fungicides are often used, which belong to heterocyclic compounds - these are various nitrogen-containing derivatives of pyrimidine, imidazole, pyrazole, etc. The advantages of these organic biocidal preparations are that they are rapidly metabolized, unlike inorganic biocides containing heavy metals $[12,13]$.

The choice of biocides should be carried out using not only test cultures, but also their associations. Also, one of the reasons for the insufficiently effective fight against biological damage is the development of resistance of micromycetes to these drugs.

The purpose of this work was to study by different methods the fungicidal properties of a number of paint coatings and biocidal preparations and to compare the resuts obtained by these methods.

\section{Materials and methods}

The study used five white paint coatings (PC) with different properties and three biocidal drugs $(\mathrm{BC})$.

PC № 1 - water-based moisture resistant latex paint intendend for walls and ceilings. Composition: vinyl acetate - ethylene dispersion, pigment fillers, functional additives, water. 
PC № 2 - water-based washable paint for mineral wall surfaces. Composition: vinyl resin, titanium dioxide, fillers, various additives, water.

PC № 3 is a water-based dispersion paint intended for painting walls and ceilings inside dry rooms and rooms with high humidity. Composition: copolymer dispersion, titanium dioxide, fillers, processing aids, fungicide, water.

PC № 4 is a water-based dispersion paint intended for walls and ceilings in rooms with normal and high humidity, as well as with possible fluctuations in humidity. Composition: acrylic copolymer dispersion, titanium dioxide, fillers, functional additives and water. than $50 \%$ ), non-cyclic acetals, aliphatic nitrogen compounds.

PC № 5 - alkali-resistant acrylate paint, used for painting concrete plinths. Ingredients: acrylic copolymer, titanium dioxide, filler, special additives, water.

BC № 1 - means for the destruction of mold. Designed for work inside dry and damp rooms, for external work on mineral (granite, brick, concrete) and wood surfaces. Composition: $9 \%$ isothiazolone derivatives. Does not stain or brighten the surface, odorless, $\mathrm{pH}=3$.

BC № 2 - water-based antiseptic impregnation, is used both to prevent bio-damage and to stop processes that have already begun. It is used to treat and protect various surfaces from mold - internal wooden walls, beams, load-bearing beams, wooden furniture and other various wooden constructions. Suitable for processing finishing materials, plasterboard, natural and artificial stone, brickwork, concrete and slate. Composition: quaternary ammonium compounds. It has a high wetting ability, it actively penetrates the treated surfaces, penetrating deeply inside and creating a protective film on them, preventing the penetration of fungal spores into the pores of the building material. It is ecologically safe, does not have strong odor, does not irritate the upper respiratory tract, is fire and explosion safe, has a $\mathrm{pH}=7$. Recommended as an additive to chalk and cement mortars, as well as to water-soluble paints against mold growth.

BC № 3 - is a transparent light-yellow liquid with a density of $1.01 \pm 0.02 \mathrm{~g} / \mathrm{ml}$, a $1 \%$ solution of the drug has a $\mathrm{pH}=3.4$. Composition: 5-chloro-2-methyl-4-isothiazolin-3-one, 2-methyl-4-isothiazolin-3-one (more than $50 \%$ ), non-cyclic acetals, aliphatic nitrogen compounds.

All biocides were used at a concentration of $10 \%$.

Two types of brick samples in the form of 20 chips were used as building materials: ceramic and silicate, as well as samples of cardboard and wood.

Samples of bricks were dipped in paint for three minutes to achieve complete coverage, excess paint was removed. Other samples were impregnated with the test biocides for three minutes. The samples were placed on a grid and left at room temperature for several days until completely dry. Samples not treated with paints or biocides served as controls. After drying, two samples were placed in Petri dishes with Czapek-Dox medium and treated with a suspension of fungal spores with a concentration of 1-1.5 million $/ \mathrm{cm}^{3}$. Spore concentration was determined using a photometer at a wavelength of $400 \mathrm{~nm}$ according to the calibration curve. The suspension was prepared under sterile conditions at 0.220 $0.440 \mathrm{D}$, corresponding to $1-1.5 \mathrm{million} / \mathrm{cm}^{3}$ of Aspergillus niger spores. Petri dishes were placed in a thermostat for 14 days at $(29 \pm 2){ }^{\circ} \mathrm{C}$

The study of the fungal resistance of paint coatings was carried out by the measuring antifungal effectiveness with zones of inhibition around wells, samples of cardboard and wood. In the method of wells and on cardboard samples, seven types of micromycetes were used as test cultures in accordance with the state standards: 1) Aspergillus niger van Tieghem; 2) Aureobasidium pullulans (de Bary) Arnaud; 3) Paecilomyces variotii Bainier; 4) Penicillium funiculosum Thom; 5) P. ochrochloron Biourge; 6) Scopulariopsis brevicaulis Bainier; 7) Trichoderma viride Pers. ex. S. F. Gray. Cultivation of micromycetes was carried out in Petri dishes with Czapek-Dox medium for two weeks. 
To study the fungal resistance by the method of wells, wells were made in the center of a Petri dish with starvation agar with a sterile scalpel. The paint coatings were placed in an individual well and inoculated with a suspension of micromycete spores with a concentration of $1-1.5$ million spores $/ \mathrm{cm}^{3}$. They were cultivated in a thermostat at $(29 \pm 2){ }^{\circ} \mathrm{C}$ for two weeks. Then, the zone of inhibition of fungal growth and the degree of of the surface of the preparations in the wells were measured.

The study of the fungal resistance of paint coatings and biocidal preparations was carried out on samples of cardboard and wood. Samples of cardboard size $3.0 \times 3.0 \mathrm{~cm}$ were double-coated or biocide-treated and dried. Test pieces of cardboard was placed in a Petri dish with a Czapek-Dox medium and inoculated with a suspension of micromycete spores with a concentration of 1-1.5 million spores $/ \mathrm{cm}^{3}$. They were cultivated in a thermostat at $(29 \pm 2){ }^{\circ} \mathrm{C}$ for one and a half weeks. Then, the zone of inhibition of fungal growth and the degree of overgrowth of the surface of the preparations on a cardboard sample were measured for 14 days.

The study of the fungal resistance of coatings by the intensity of the development of mold fungi on wood samples was carried out on samples with a size of $3.5 \times 3.5 \mathrm{~cm}$ and a thickness of $0.9 \mathrm{~cm}$. The samples were covered with a double layer of paintwork or treated with a biocide and dried. The samples were placed in Petri dishes on the Czapek-Dox medium and infected with a spore suspension of a mixture of micromycetes with a concentration of $1-1.5$ million spores $/ \mathrm{cm}^{3}$. The plates were incubated at $(29 \pm 2){ }^{\circ} \mathrm{C}$ for two weeks. Then, the zone of inhibition of fungal growth and the degree of overgrowing of the surface of the preparations were measured.

The degree of coverage of the PC samples in the wells, as well as of cardboard and wood samples with spore-bearing mycelium, was determined as a percentage of the original sample area. The zone of inhibition of the growth of micromycetes was defined as the distance from the edge of the sample to the zone of the beginning of mycelium growth. The measurements were carried out in duplicate. In the tables of the results section, the data on the percentage of overgrowing of the surfaces differ by no more than $15 \%$.

\section{Results}

The study of fungal resistance of coatings on samples of ceramic and silicate bricks was carried out using Aspergillus niger as a biodestructor due to the fact that this micromycete is resistant to various biocidal preparations and antifungal paint coatings, and is also easily distinguishable on white paint. In addition, it is recommended as a test culture in the standards for determining fungal resistance and was previously isolated from biotereriorated building materials [11].

PC № 1 had a fungicidal effect on the samples of ceramic bricks, the rest of the PCs showed the growth of the A.niger fungus on the sample itself (Table 1). All investigated biocides protected both ceramic and silicate bricks. The least affected by $A$. niger were the samples of silicate bricks coated with paintwork No. 1,3 and 5. All investigated biocidal preparations had protective properties on the samples of silicate brick (Table 2).

The study of fungal resistance of paint coatings by the method of wells was carried out using individual test cultures for infecting paintwork. The degree of overgrowth of the surface of the paint coatings in the wells and the zones of inhibition of the growth of micromycetes are presented in tables 3 and 4.

PC № 1 and № 3 proved to be the most resistant to the effects of all micromycetes. Fungal species such as Aspergillus niger and Trichoderma viride, are resistant to coatings and many fungicides, did not grow directly on the coating and formed an area around the coated well in which no fungal growth was observed either (Table 4). 
Table 1. Growth of Aspergillus niger on ceramic brick samples coated with protective agents.

\begin{tabular}{|c|c|c|c|}
\hline \multicolumn{2}{|c|}{ Protective agent } & \multirow{2}{*}{ Inhibition zone, mm } & $\begin{array}{c}\text { Overgrowth of the } \\
\text { surface, \% }\end{array}$ \\
\cline { 1 - 2 } PC & BC & $16 \pm 3$ & 0 \\
\hline № 1 & - & $12 \pm 2$ & 70 \\
\hline № 3 3 & - & 0 & 30 \\
\hline № 4 & - & 0 & 30 \\
\hline № 5 & - & 0 & 30 \\
\hline- & № 1 & $14 \pm 2$ & 0 \\
\hline- & № 2 & $10 \pm 1$ & 0 \\
\hline- & № 3 & $12 \pm 2$ & 0 \\
\hline
\end{tabular}

Table 2. Growth of Aspergillus niger on sand-lime brick samples coated with protective agents.

\begin{tabular}{|c|c|c|c|}
\hline \multicolumn{2}{|c|}{ Protective agent } & \multirow{2}{*}{ Inhibition zone, mm } & $\begin{array}{c}\text { Overgrowth of } \\
\text { the surface, \% }\end{array}$ \\
\cline { 1 - 2 } PC & BC & $18 \pm 3$ & 0 \\
\cline { 1 - 2 } № 1 & - & 0 & 70 \\
\hline № 2 & - & $15 \pm 3$ & 0 \\
\hline № 3 & - & 0 & 30 \\
\hline № 4 & - & $12 \pm 1$ & 0 \\
\hline № 5 & - & $16 \pm 2$ & 0 \\
\hline- & № 1 & $12 \pm 1$ & 0 \\
\hline- & № 2 & $15 \pm 3$ & 0 \\
\hline- & № 3 & & \\
\hline
\end{tabular}

Table 3. Overgrowth of paint coating surface by test cultures of micromycetes, $\%$.

\begin{tabular}{|c|c|c|c|c|c|}
\hline \multirow{2}{*}{ Micromycetes } & \multicolumn{5}{|c|}{ Paint coating } \\
\cline { 2 - 6 } & № 1 & № 2 & № 3 & № 4 & № 5 \\
\hline Aspergillus niger & 0 & 60 & 0 & 70 & 50 \\
\hline Paecilomyces variotii & 0 & 0 & 0 & 30 & 25 \\
\hline Penicillium funiculosum & 0 & 20 & 0 & 30 & 0 \\
\hline Penicillium ochro-chloron & 0 & 60 & 0 & 20 & 0 \\
\hline Scopulariopsis brevicaulis & 0 & 10 & 0 & 30 & 20 \\
\hline Trichoderma viride & 0 & 40 & 0 & 60 & 50 \\
\hline Aureobasidium pullulans & 0 & 25 & 0 & 25 & 40 \\
\hline
\end{tabular}

Table 4. Zones of inhibition of test-micromycetes around paint coating, mm.

\begin{tabular}{|c|c|c|c|c|c|}
\hline \multirow{2}{*}{ Micromycetes } & \multicolumn{5}{|c|}{ Paint coating } \\
\cline { 2 - 6 } & № 1 & № 2 & № 3 & № 4 & № 5 \\
\hline Aspergillus niger & $20 \pm 3$ & 0 & $20 \pm 3$ & 0 & 0 \\
\hline Paecilomyces variotii & $20 \pm 1$ & $10 \pm 2$ & $20 \pm 2$ & 0 & 0 \\
\hline Penicillium funiculosum & $25 \pm 3$ & 0 & $5 \pm 1$ & 0 & $10 \pm 1$ \\
\hline Penicillium ochro-chloron & $25 \pm 2$ & 0 & $20 \pm 2$ & 0 & $15 \pm 2$ \\
\hline Scopulariopsis brevicaulis & $25 \pm 3$ & 0 & $10 \pm 2$ & 0 & 0 \\
\hline Trichoderma viride & $25 \pm 4$ & 0 & $10 \pm 2$ & 0 & 0 \\
\hline Aureobasidium pullulans & $20 \pm 1$ & 0 & $10 \pm 1$ & 0 & 0 \\
\hline
\end{tabular}

The analysis of fungal resistance of paint and varnish coatings and biocidal biocidal preparations on cardboard samples was also carried out using individual test cultures. According to the results of the experiment (table 5) PC № 1 and № 3 turned out to be the 
most resistant to the effects of all investigated micromycetes. Within two weeks, there was a slight decrease in the zone of inhibition around these samples, but no contamination occurred directly on the samples themselves. Of the biocides, only BC № 1 had fungicidal properties, while the zone of inhibition of micromycete growth did not change for two weeks. The least pronounced protective effect was possessed by PC № 5, while after 14 days the zone of inhibition significantly decreased and was completely absent in Penicillium funiculosum, T. viride, Aureobasidium pullulans. All types of micromycetes damaged PC № 2 .

Table 5. Overgrowth of the surface of cardboard samples with micromycetes (14 days), \%.

\begin{tabular}{|c|c|c|c|c|c|c|c|c|}
\hline \multirow{2}{*}{ Micromycetes } & \multicolumn{9}{|c|}{ PC } & \multicolumn{9}{|c|}{ Protective agent } \\
\cline { 2 - 9 } & № 1 & № 2 & № 3 & № 4 & № 5 & № 1 & № 2 & № 3 \\
\hline Aspergillus niger & 0 & 95 & 0 & 60 & 0 & 0 & 30 & 20 \\
\hline Aspergillus ustus & 0 & 80 & 0 & 45 & 0 & 0 & 20 & 20 \\
\hline $\begin{array}{c}\text { Penicillium } \\
\text { funiculosum }\end{array}$ & 0 & 85 & 0 & 75 & 10 & 0 & 10 & 15 \\
\hline $\begin{array}{c}\text { Penicillium } \\
\text { ochro-chloron }\end{array}$ & 0 & 50 & 0 & 40 & 0 & 0 & 0 & 0 \\
\hline $\begin{array}{c}\text { Scopulariopsis } \\
\text { brevicaulis }\end{array}$ & 0 & 85 & 0 & 35 & 10 & 0 & 20 & 0 \\
\hline $\begin{array}{c}\text { Trichoderma } \\
\text { viride }\end{array}$ & 0 & 50 & 0 & 40 & 10 & 0 & 40 & 25 \\
\hline $\begin{array}{c}\text { Aureobasidium } \\
\text { pullulans }\end{array}$ & 0 & 25 & 0 & 25 & 40 & 0 & 25 & 25 \\
\hline
\end{tabular}

Table 6. Growth of a mixture of micromycetes on wood samples coated with protective agents.

\begin{tabular}{|c|c|c|c|}
\hline \multicolumn{2}{|c|}{ Protective agent } & \multirow{2}{*}{ Overgrowth of the surface, \% } \\
\cline { 1 - 2 } PC & BC & Inhibition zone, $\mathrm{mm}$ & 0 \\
\hline № 1 & - & $18 \pm 1$ & 30 \\
\hline № 2 & - & 0 & 0 \\
\hline № 3 & - & $13 \pm 1$ & 0 \\
\hline № 4 & - & $10 \pm 1$ & 25 \\
\hline № 5 & - & 0 & 0 \\
\hline- & № 1 & $17 \pm 3$ & 30 \\
\hline- & № 2 & 0 & 20 \\
\hline- & № 3 & 0 & 2 \\
\hline
\end{tabular}

The analysis of fungal resistance of paint and varnish coatings and biocidal preparations on wood samples was carried out in accordance with the state standard, using a mixture of conidia of various micromycetes for inoculating samples. The results of the study after 14 days of growth of micromycetes are presented in table 6 .

Wood samples coated with PC № 1, 3, 4, as well as BC № 1, were not overgrown with micromycetes. A zone of growth inhibition of the studied fungi was observed for the same agents. PC № 2 and 5, as well as BC № 2 and 3, were overgrown with micromycetes by 20 $30 \%$ and did not form a zone of inhibition of the growth of micromycetes. 


\section{Discussion}

Comparison of the methods for determining the fungal resistance of $\mathrm{PC}$ and $\mathrm{BC}$ is presented in table 7. Most of the methods obtained similar results. The exception is the method of processing brick chips, where positive results were shown by BC № 2 and 3, which do not show their effect on cardboard and wood samples. Perhaps, due to the porous surface and unequal geometric dimensions of the brick samples, they should not be used for the analysis of the fungal resistance of $\mathrm{PC}$ and $\mathrm{BC}$.

To study fungal resistance by the method of wells and on cardboard samples, while a mixture of micromycete conidia was used for inoculation, and a suspension of conidia of individual micromycetes was used to inoculate wood samples, which significantly reduces the complexity of the study. While, the results obtained by the method of wells and cardboard samples completely coincide, and then the results using on wood samples the results differ only for one PC № 4. Therefore, to study the fungal resistance of PC and BC, it is better to use a less laborious option with a mixture of conidia of different micromycetes. Considering this, there is no need to use wood samples to study fungal resistance. They can be replaced with cheaper cardboard samples, and the well method can be used for rapid tests.

Table 7. The presence of overgrowth on the surfaces of the PC and BC with different research methods.

\begin{tabular}{|c|c|c|c|c|c|}
\hline \multirow{2}{*}{ Protective agent } & \multicolumn{5}{|c|}{ Research method } \\
\cline { 2 - 6 } & Wells & $\begin{array}{c}\text { On cardboard } \\
\text { samples }\end{array}$ & $\begin{array}{c}\text { On wood } \\
\text { samples }\end{array}$ & $\begin{array}{c}\text { On ceramic } \\
\text { bricks }\end{array}$ & $\begin{array}{c}\text { On silicate } \\
\text { bricks }\end{array}$ \\
\hline PC № 1 & - & - & - & - & - \\
\hline PC № 2 & + & + & + & + & + \\
\hline PC № 3 & - & - & - & + & - \\
\hline PC № 4 & + & + & - & + & + \\
\hline PC № 5 & + & + & + & + & - \\
\hline ВC № 1 & - & - & - & - & - \\
\hline ВC № 2 & - & + & + & - & - \\
\hline BC № 3 & - & + & + & - & - \\
\hline
\end{tabular}

\section{Conclusions}

Thus, the comparison of methods for determining fungal resistance makes it possible to simplify and reduce the cost of studies aimed at the selection of finishing materials and biocides.

\section{References}

1. F. Cappitelli, C. Sorlini, Appl. Environ. Microbiol. 74(3), 564-569 (2008) DOI:10.1128/AEM.01768-07

2. B. Andersen, J.C. Frisvad, I. Søndergaard, I.S. Rasmussen, L.S. Larsen, Appl. Environ. Microbiol. 77(12), 4180-4188 (2011) DOI: 10.1128/AEM.02513-10 
3. J.S. Webb, M. Nixon, I.M. Eastwood, M. Greenhalgh, G.D. Robson, P.S. Handley, Appl. Environ. Microbiol. 66(8), 3194-3200 (2000) DOI: 10.1128/aem.66.8.31943200.2000.

4. X. Dai, H. Wang, L.K. Ju, G. Cheng, H. Cong, B.Z. Newby, Internat. Biodeter. \& Biodegradation 115, 1-10 (2016) DOI:10.1016/j.ibiod.2016.07.009

5. H. Viitanen, In book: Mass Transfer - Advanced Aspects (2011) DOI: 10.5772/21184

6. M.V. Ljaljeviã, G.J.B. Vukojeviã, Proc. Nat. Sci. Matica Srpska Novi Sad 116, 245 251 (2009)

7. B.G. Shelton, K.H. Kirkland, W.D. Flanders, G.K. Morris, Appl. Environ. Microbiol. 68(4), 1743-1753 (2002) DOI: 10.1128/AEM.68.4.1743-1753.2002.

8. B. Zyska, Mikologia Lekarska 8(3), 127-140 (2001)

9. A.M. Ivanovo, I. Kirtsideli, Mikologiya I Fitopatologiya 41(1), 40-47 (2007)

10. A.M. Moldoveanu (2015) DOI: 10.5772/59727.

11. T. Velikova, E. Trepova, T. Rosen, Communicating Current Research and Technological Advances, Microbiology Series, Formatex. 1(3), 152-159 (2011)

12. M. Edgeva, M.S. Allena, D. Turnera, J. Robinsona, K. Sealb, Prigress in Organic Coatings 43(1-3), 10-17 (2001) DOI:10.1016/S0300-9440(01)00244-2

13. V. Strokova, V. Nelyubova, M. Rykunova, MATEC Web of Conferences 251, 01018, (2018) DOI:10.1051/matecconf/201825101018 